\title{
Experimental Evidence of Fluid Secretion of Rabbit Lacrimal Gland Duct Epithelium
}

\author{
Máté Katona, ${ }^{1,2}$ Eszter Vizvári, ${ }^{3}$ Lukács Németh, ${ }^{4}$ Andrea Facskó,,${ }^{3}$ Viktória Venglovecz, ${ }^{2}$ \\ Zoltán Rakonczay Jr, ${ }^{1}$ Péter Hegyi, ${ }^{1}$ and Edit Tóth-Molnár ${ }^{2,3}$ \\ ${ }^{1} 1$ st Department of Internal Medicine, University of Szeged, Szeged, Hungary \\ ${ }^{2}$ Department of Pharmacology and Pharmacotherapy, University of Szeged, Szeged, Hungary \\ ${ }^{3}$ Department of Ophthalmology, University of Szeged, Szeged, Hungary \\ ${ }^{4}$ Department of Medicinal Chemistry, University of Szeged, Szeged, Hungary
}

Correspondence: Edit Tóth-Molnár, Department of Ophthalmology, University of Szeged, 6720 Szeged, Korányi fasor 10-11, Hungary; tme@tmedit.hu.

Submitted: January 24, 2014

Accepted: May 12, 2014

Citation: Katona M, Vizvári E, Németh $\mathrm{L}$, et al. Experimental evidence of fluid secretion of rabbit lacrimal gland duct epithelium. Invest Ophthalmol Vis Sci. 2014;55:4360-4367. DOI: $10.1167 /$ iovs. 14-14025
Purpose. To investigate the osmotic water permeability of lacrimal gland (LG) duct epithelium by means of calculation of filtration permeability and to investigate LG ductal fluid secretion.

Methods. Experiments were performed on isolated rabbit LG duct segments maintained in short-term culture. Osmotically determined fluid movement or fluid secretion into the closed intraluminal space of cultured LG interlobular ducts was analyzed using video microscopic technique.

Results. The end of the LG ducts sealed after overnight incubation forming a closed luminal space. For the calculation of osmotic water permeability, ducts were initially perfused with isotonic HEPES buffered solution, and then with hypotonic HEPES buffered solution. Filtration permeability was calculated from the initial slope of the relative volume increase. Secretory responses to carbachol or to forskolin stimulation were also investigated. Forskolin stimulation resulted in a rapid and sustained secretory response in both solutions. Forskolinstimulated fluid secretion was completely inhibited by bumetanide both in HEPES buffered and in $\mathrm{HCO}_{3}-/ \mathrm{CO}_{2}$ buffered solutions, suggesting the central role of $\mathrm{Na}^{+}-\mathrm{K}^{+}-2 \mathrm{Cl}^{-}$ cotransporter type 1 (NKCC1). Administration of carbachol initiated a rapid but short secretory response in both HEPES buffered and in $\mathrm{HCO}_{3}{ }^{-} / \mathrm{CO}_{2}$ buffered solutions. Atropine completely abolished the carbachol-evoked fluid secretion.

Concuusions. A new method was introduced to investigate LG duct function. Water permeability of rabbit LG duct epithelium was measured by calculating filtration permeability. Fluid secretion of LG duct cells induced by carbachol or forskolin was also demonstrated. These results provide calculated values of lacrimal duct osmotic permeability and direct experimental evidence of LG duct fluid secretion.

Keywords: lacrimal gland, epithelial cells, lacrimal gland duct, fluid secretion
B oth the balanced electrolyte, and mucin protein composition, as well as the appropriate amount of fluid secreted by the lacrimal gland (LG) are essential for maintaining preocular tear film integrity. Dysfunction of the lacrimal functional unit can lead to the development of dry eye causing a wide spectrum of ocular surface damage. ${ }^{1-3}$ Dry eye disease has become an emerging health problem in industrialized countries worldwide. A more detailed understanding of the LG function can lead to the development of specific therapeutic modalities.

Similarly to other exocrine tubuloacinar glands, LG is mainly composed of three types of cells: acinar, duct, and myoepithelial cells. 4,5 Functions of acinar cells are widely studied, resulting in a broad spectrum of information. ${ }^{6-9}$ Contrarily, much less is known about the possible secretory function of duct cells. It has been proposed that primary acinar fluid is modified by ductal secretory processes: an elevated $\mathrm{K}^{+}$and $\mathrm{Cl}^{-}$ content of the final product evolves during passage of fluid through the ductal tree. ${ }^{6,7,10}$ However, the role of LG duct epithelium on fluid, electrolyte, and protein secretion is not well understood.
New methods have been published to study LG duct epithelium during the past few years. Ubels and colleagues ${ }^{11}$ collected duct cells from frozen rat LG sections using a laser capture microdissection technique. Numerous genes coding basolateral-to-apical $\mathrm{K}^{+}$secretion-related transport proteins were found in duct cells. Another experimental method to study LG function was described by our laboratory. ${ }^{12}$ The new isolation technique resulted in viable duct segments for functional studies. The role and regulation of various ion transporters in the lacrimal duct can be studied with the use of isolated, short-term cultured duct segments. Our results showed the functional presence of a $\mathrm{Na}^{+}$-dependent proton efflux mechanism $\left(\mathrm{Na}^{+} / \mathrm{H}^{+}\right.$exchanger; $\left.\mathrm{NHE}\right)$ and $\mathrm{a} \mathrm{Cl}^{-}$dependent $\mathrm{HCO}_{3}{ }^{-}$efflux mechanism (anion exchanger; AE) using $\mathrm{pH}$-sensitive fluorescent dye in LG duct cells. Overall actions of basolaterally- and apically- located ion transporters produce an osmotic gradient, which determine the direction of water flow. Water passively follows secreted ions depending on the osmotic gradient.

The underrepresentation of studies concerning lacrimal duct epithelial cells is in striking contrast to the information 
that has been gathered from the duct system of the pancreas or salivary glands. The role of duct system in different glands varies on a wide scale. Pancreatic ducts have an important role in secretion of $\mathrm{HCO}_{3}{ }^{-}$-rich fluid. ${ }^{13-17}$ The duct cells in salivary glands seem to secrete $\mathrm{K}^{+}$and $\mathrm{HCO}_{3}{ }^{-}$and reabsorb $\mathrm{Na}^{+}$and $\mathrm{Cl}^{-}$without water movement. ${ }^{18-21}$ Although LG duct epithelial cells supposedly participate in ion transport processes, there is no data supported by experimental results regarding the contribution of duct cells in fluid secretion of the gland. In addition, there is no data available about water permeability of LG duct epithelium.

The aims of the present work were to determine the osmotic water permeability of duct epithelium by means of calculation of filtration permeability $\left(P_{\mathrm{f}}\right)$, and to investigate LG duct fluid secretion by means of measurement of fluid secretion evoked by potential agonists (forskolin and carbachol).

\section{Materials ANd Methods}

\section{Animals}

Adult male New Zealand white rabbits weighing 2 to $2.5 \mathrm{~kg}$ were used (Devai Farm, Kondoros, Hungary). The animals were narcotized with a mixture of ketamine $(10 \mathrm{mg} / \mathrm{kg}$, intravenously) and xylazine $(3 \mathrm{mg} / \mathrm{kg}$, intravenously) and were euthanized with pentobarbital overdose $(80 \mathrm{mg} / \mathrm{kg}$, intravenously). All experiments were conducted in compliance with the ARVO Statement for the Use of Animals in Ophthalmic and Vision Research. The protocol has been approved by the ethical committee for the Protection of Animals in Research of the University of Szeged, Szeged, Hungary and conformed to the Directive 2010/63/EU of the European Parliament.

\section{Solutions and Chemicals for Isolation, Culture, and Superfusion of LG Ducts}

Isolation solution contained Dulbecco's modified Eagle's medium (DMEM) supplemented with $100 \mathrm{U} / \mathrm{mL}$ collagenase (Worthington, Lakewood, NJ, USA) and $1 \mathrm{mg} / \mathrm{mL}$ BSA. Storage solution contained DMEM and 3\% (wt/vol) BSA. Culture solution contained McCoy's 5A tissue culture medium, $10 \%$ (vol/vol) fetal calf serum, and $2 \mathrm{mM}$ glutamine. Media supplements (DMEM, McCoy, fetal calf serum, glutamine, and BSA) were purchased from Sigma-Aldrich (Budapest, Hungary).

Standard HEPE buffered solution contained (mM): $140 \mathrm{NaCl}$ (67.5 NaCl in case of hypotonic solution: $145 \mathrm{mosM}$ ), $5 \mathrm{KCl}, 2$ $\mathrm{CaCl}_{2}, 1 \mathrm{MgCl}_{2}, 10 \mathrm{D}$-glucose, and $10 \mathrm{Na}$-HEPES and $\mathrm{pH}$ was set to 7.4 with $\mathrm{HCl}$ at $37^{\circ} \mathrm{C}(290 \mathrm{mosM})$.

The standard $\mathrm{HCO}_{3}{ }^{-} / \mathrm{CO}_{2}{ }^{-}$buffered solution contained (mM): $115 \mathrm{NaCl}, 25 \mathrm{NaHCO}_{3}, 5 \mathrm{KCl}, 1 \mathrm{CaCl}_{2}, 1 \mathrm{MgCl}_{2}, 10 \mathrm{D}-$ glucose and was gassed with $95 \% \mathrm{O}_{2} / 5 \% \mathrm{CO}_{2}$ at $37^{\circ} \mathrm{C}$.

Carbamoylcholine chloride (Carbachol), forskolin, bumetanide, DIDS, and 5-(N-ethyl-N-isopropyl)amiloride (EIPA) were obtained from Sigma-Aldrich.

\section{Isolation and Culture of Lacrimal Duct Segments}

Rabbit LG interlobular ducts were isolated as previously described by our laboratory. ${ }^{12}$ Briefly LGs were dissected and transferred to a sterile small flat-bottom glass flask containing a cold $\left(+4^{\circ} \mathrm{C}\right)$ storage solution. Isolation solution was injected into the interstitium of the glands and the tissue pieces were transferred to a glass flask containing $2 \mathrm{~mL}$ of isolation solution for incubation in a shaking water bath at $37^{\circ} \mathrm{C}$. Isolation solution was removed after incubating for 25 minutes and $5 \mathrm{~mL}$ of fresh cold storage $\left(+4^{\circ} \mathrm{C}\right)$ solution was added to the flask. Lacrimal gland tissue samples were transferred to a glass microscope slide and viewed under stereo microscope. Interlobular ducts were microdissected and after microdissection, intact LG ducts were transferred to the culture solution in a petri dish. Ducts were cultured overnight in a $37^{\circ} \mathrm{C}$ incubator gassed with $5 \% \mathrm{CO}_{2} / 95 \% \mathrm{O}_{2}$.

\section{Measurement of Osmotic Water Permeability and Fluid Secretion of LG Interlobular Duct Epithelium}

The ends of LG ducts seal during overnight incubation forming a closed luminal space. Secretory processes (or osmoticallydetermined fluid movement) of duct epithelium into the closed intraluminal space result in swelling of the ducts as the luminal space fills with the secreted fluid as seen in the case of isolated pancreatic ducts. The change in duct volume can be analyzed using the video microscopic method. ${ }^{17,22,23}$ Cultured LG duct segments were carefully transferred to a coverslip pretreated with diluted poly-l-lysine (diluted in distilled water, ratio $=1: 9$; Sigma-Aldrich). The coverslip formed the base of a perfusion chamber mounted on an inverted microscope (Olympus Ltd., Budapest, Hungary). The chamber was perfused with solutions via an infusion pump at approximately $2.5 \mathrm{~mL} / \mathrm{min}$ at $37^{\circ} \mathrm{C}$. Ducts were visualized at high magnification ( $\times 20$ objective). Bright-field images were acquired at set time intervals ( 5 seconds in the case of osmotic permeability measurements and 1 minute in the case of ductal fluid secretion experiments) using a charge-coupled digital camera device coupled to a personal computer. Both the duration of experiments and the time intervals between images were defined in Xcellence (Olympus Ltd.) imaging software. An image series in tagged image file format was generated containing all of the images collected from the same experiment. Scion Image (Scion Corporation, Frederick, MD, USA) software was used to obtain values and analyze changes in the area corresponding to the luminal space in each image.

The initial lumen length $\left(L_{0}\right)$ and the lumen area $\left(A_{0}\right)$ were measured directly from the pixel intensities on the first image. The lumen diameter was calculated assuming the cylindrical setup of the duct, from the formula $2 \mathrm{R}=A_{0} / L_{0}$. The luminal surface area was calculated as $2 \pi R_{0} L_{0}$, also assuming cylindrical geometry. Measurements from subsequent individual images were normalized to the first lumen area in the series $\left(\mathrm{A}_{0}\right)$ thus giving values for the relative area $\left(A_{\mathrm{R}}=A / A_{0}\right)$. Relative luminal volume $\left(V_{\mathrm{R}}=V / V_{0}\right)$ of the ducts was then calculated from the relative image area. These calculations were done using Scion Image and Microsoft Excel software (Microsoft, Redmond, WA, USA).

Luminal volume change after exposure to hypotonic solution was measured for the calculation of osmotic permeability as follows: ducts were perfused with isotonic HEPES buffered solution (290 mosM) for 5 minutes after equilibration, then the perfusate was changed to hypotonic HEPES buffered solution (145 mosM). ${ }^{24}$

The osmotic water permeability constant $\left(\left[P_{\mathrm{f}}\right]=\mu \mathrm{m} / \mathrm{s}\right)$ was calculated using the initial volume $\left(V_{0}=\pi R_{0}^{2} L_{0}\right)$, the initial slope of the relative volume increase $\left(d\left(V / V_{0}\right) / d t\right)$, the initial luminal surface area $\left(S_{0}=2 \pi R_{0} L_{0}\right)$, and the molar volume of water $\left(V_{\mathrm{w}}=18 \times 10^{12} \mu \mathrm{M}\right)$ as follows ${ }^{25}$ :

$$
P_{\mathrm{f}}=\left[V_{0} d\left(V / V_{0}\right) / d t\right] /\left[S_{0} V_{\mathrm{w}}\left(o s m_{\mathrm{in}}-o s m_{\mathrm{out}}\right)\right]
$$

where $o s m_{\text {in }}-o s m_{\text {out }}$ is the difference between inner and outer 


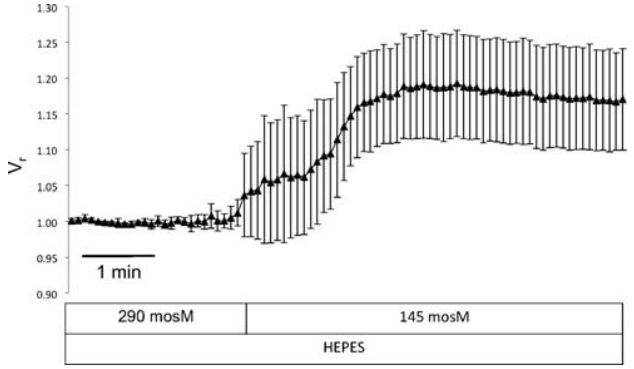

Figure 1. Osmotic permeability of rabbit interlobular duct epithelium. Interlobular ducts were isolated from the LG of rabbits. Changes in the relative luminal volume $\left(V_{\mathrm{r}}\right)$ induced by a $50 \%$ reduction in the osmolarity of the perfusate are shown. Measurements were performed by video microscopy. Bright field images were captured at 5-second intervals. Data was obtained from nine ducts isolated from three different animals and is presented as the mean \pm SEM.

mediums osmolarity. In this case $\operatorname{osm}_{\mathrm{in}}=290 \mathrm{mOsm}$ and $o s m_{\text {out }}=145 \mathrm{mOsm}$.

In the case of fluid secretion measurements, carbachol or forskolin was added to the perfusate after 10-minutes superfusion with HEPES buffered or $\mathrm{HCO}_{3}{ }^{-} / \mathrm{CO}_{2}$ buffered solution. At the end of each experiment, perfusion was changed to hypotonic solution for 5 minutes in order to confirm epithelial integrity. Complete sealing was proved by rapid swelling of the ducts as a response to hypotonic challenge. Data obtained from ducts not showing swelling response was discarded.

\section{Statistical Analysis}

Data is presented as means $\pm \mathrm{SEM}$, where the value of $n$ is the number of ducts. One-way ANOVA followed by Bonferroni post hoc test was used for statistical comparison of data, $P$ less than 0.05 was chosen as the limit for statistical significance.

\section{RESULTS}

\section{Osmotic Water Permeability of LG Interlobular Duct Epithelium}

The luminal area increased after exposure to the hypotonic solution indicating that the $\mathrm{NaCl}$ gradient caused rapid water flux into the closed luminal space. $P_{\mathrm{f}}$ was $60.53 \pm 19.76 \mu \mathrm{m} / \mathrm{s}$ $(n=9$, from three different animals). Figure 1 shows the changes in the luminal volume after the change in bath osmolarity.

\section{Forskolin-Stimulated Fluid Secretion of Interlobular Ducts}

Effects of forskolin stimulation on secretion of LG ducts were investigated both in HEPES buffered and in $\mathrm{HCO}_{3}{ }^{-} / \mathrm{CO}_{2}$ buffered solutions. In the first series of the experiments, ducts were superfused with HEPES buffered solution for 10 minutes, and then $10 \mu \mathrm{M}$ forskolin was added to the bath. Ducts remained unchanged in HEPES buffered solution (secretory rate: $-2.2 \pm 18.7 \mathrm{pL} / \mathrm{min} / \mathrm{mm}^{2}$ ), while during forskolin stimulation, rapid, sustained swelling response was observed (secretory rate in the first 10 minutes of stimulation: $379.9 \pm$ $54.4 \mathrm{pL} / \mathrm{min} / \mathrm{mm}^{2}$, in the first 15 minutes of stimulation: 327.4 $\pm 41.6 \mathrm{pL} / \mathrm{min} / \mathrm{mm}^{2}$; Fig. $2 \mathrm{~A}$ ).

In order to evaluate the potential role of $\mathrm{HCO}_{3}{ }^{-}$transporters in forskolin-evoked fluid secretion, ducts were superfused with $\mathrm{HCO}_{3}{ }^{-} / \mathrm{CO}_{2}$ buffered solutions for 10 minutes, and then forskolin was added to the bath. There was no detectable secretion in $\mathrm{HCO}_{3}{ }^{-} / \mathrm{CO}_{2}$ buffered solution (secretory rate: 3.6 $\pm 11 \mathrm{pL} / \mathrm{min} / \mathrm{mm}^{2}$ ), while rapid secretion could be observed as an effect of forskolin stimulation (secretory rate in the first 10 minutes of stimulation: $408.3 \pm 69.5 \mathrm{pL} / \mathrm{min} / \mathrm{mm}^{2}$, in the first 15 minutes of stimulation: $355.1 \pm 64 \mathrm{pL} / \mathrm{min} / \mathrm{mm}^{2}$; Fig. 2B). See Supplementary Video S1 for the effect of forskolin stimulation on ductal fluid secretion in $\mathrm{HCO}_{3}{ }^{-} / \mathrm{CO}_{2}$ buffered solution. Figure 3 shows photo series of swelling duct deriving from the video.

The secretory effect of forskolin did not differ in HEPES or $\mathrm{HCO}_{3}{ }^{-} / \mathrm{CO}_{2}$ buffered solution. The sensitivity of forskolinevoked secretion to inhibitors of known basolateral ion transporters was then investigated in the presence and in the absence of $\mathrm{HCO}_{3}{ }^{-}$.

\section{Effects of Bumetanide on Fluid Secretion}

Since rabbit LG interlobular ducts are able to secrete fluid in response to forskolin stimulation in HEPES buffered (nominally $\mathrm{HCO}_{3}{ }^{-}$free) solution (see above), a different anion than $\mathrm{HCO}_{3}{ }^{-}$, most probably $\mathrm{Cl}^{-}$can be the anionic driving force of fluid secretion. To investigate the transporter responsible for basolateral $\mathrm{Cl}^{-}$uptake, we tested the role of NKCC1 by administration of the cotransport inhibitor bumetanide. Bumetanide $(100 \mu \mathrm{M})$ completely blocked forskolin-evoked fluid secretion in HEPES buffered $\left(\mathrm{HCO}_{3}{ }^{-}\right.$free), and also in $\mathrm{HCO}_{3}{ }^{-} / \mathrm{CO}_{2}$ buffered solutions (Figs. $4 \mathrm{~A}, 4 \mathrm{~B}$ ). Bumetanide was applied after 10 minutes of stimulation with forskolin in these experiments. Effect of preincubation with bumetanide on forskolin-evoked fluid secretion in $\mathrm{HCO}_{3}{ }^{-} / \mathrm{CO}_{2}{ }^{-}$buffered solution can be seen on Figure 4C.
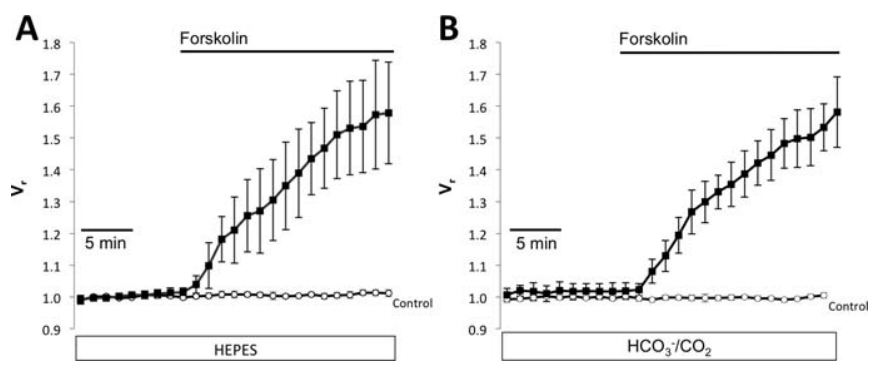

Figure 2. Effect of forskolin on ductal fluid secretion in rabbit LG interlobular ducts in the presence or in the absence of HCO ${ }_{3}^{-}$. (A) Ducts were superfused with HEPES-buffered solution throughout the experiments. From 10 minutes, ducts were exposed either to $10 \mu \mathrm{M}$ forskolin (filled square) or to no agonist (empty circle). (B) Ducts were superfused with HEPES-buffered solution for 10 minutes (data not shown) and then the perfusate was switched to $\mathrm{HCO}_{3}{ }^{-} / \mathrm{CO}_{2}$ buffered solution. After 10 minutes of superfusion with $\mathrm{HCO}_{3}{ }^{-} / \mathrm{CO}_{2}$ buffered solution, ducts were exposed either to $10 \mu \mathrm{M}$ forskolin (filled square) or to no agonist (empty circle). Changes in relative luminal volume ( $\left.V_{\mathrm{r}}\right)$ are shown. Data was obtained from five ducts isolated from at least three different animals in each series and is presented as the mean \pm SEM. 


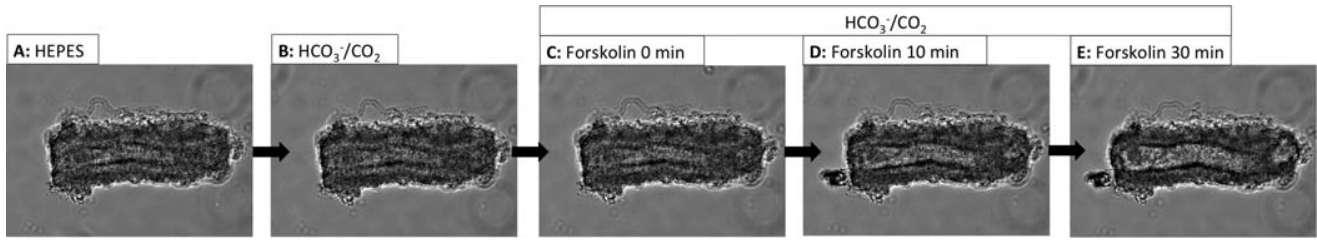

FiguRE 3. Photo series of secreting isolated rabbit LG duct segment in response to forskolin stimulation. (A) Isolated LG duct segment in HEPES buffered solution. (B) Isolated LG duct segment in $\mathrm{HCO}_{3}{ }^{-} / \mathrm{CO}_{2}$ buffered solution. (C) The beginning of $10 \mu \mathrm{M}$ forskolin stimulation in $\mathrm{HCO}_{3}{ }^{-} / \mathrm{CO}_{2}$ buffered solution. (D) Swelling response of duct segment after 10 minutes of forskolin stimulation in $\mathrm{HCO}_{3}-/ \mathrm{CO}_{2}$ buffered solution. (E) Swelling response of duct segment after 30 minutes of forskolin stimulation in $\mathrm{HCO}_{3}{ }^{-} / \mathrm{CO}_{2}$ buffered solution.

\section{Role of Basolateral $\mathrm{HCO}_{3}{ }^{-}$Transporters in Fluid Secretion}

To further investigate the contribution of basolateral $\mathrm{HCO}_{3}{ }^{-}$ and $\mathrm{Cl}^{-}$transporters, we tested the effects of basolateral transport inhibitors EIPA $(3 \mu \mathrm{M})$ and DIDS $(100 \mu \mathrm{M})$. In $\mathrm{HCO}_{3}{ }^{-}$ buffered solution, administration of EIPA and DIDS did not significantly alter the secretory rates (Fig. 4D).

These results suggest the key role of $\mathrm{Cl}^{-}$transport in fluid secretion in rabbit LG interlobular ducts.
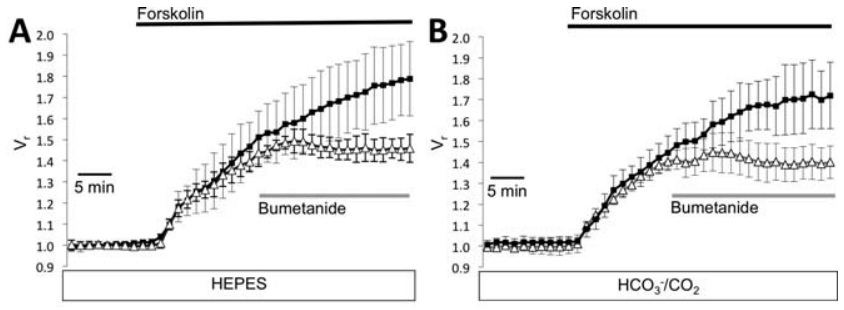

C
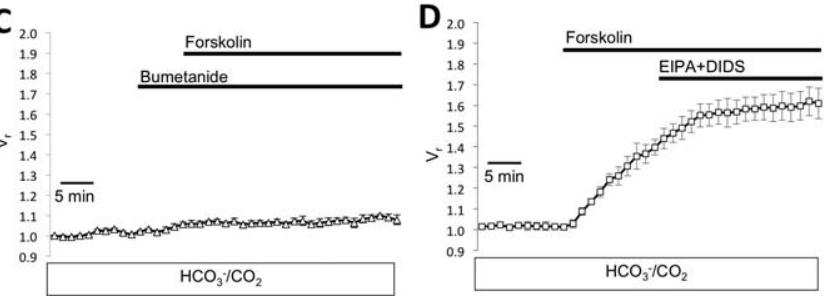

Figure 4. Effects of bumetanide, EIPA, and DIDS on forskolin-evoked ductal fluid secretion in rabbit LG interlobular ducts. (A) Ducts were superfused with HEPES buffered solution throughout the experiments. From 10 minutes, ducts were exposed to $10 \mu \mathrm{M}$ forskolin, from 20 minutes, ducts were exposed either to no blocker (only forskolin stimulation, filled square) or to $100 \mu \mathrm{M}$ bumetanide (empty triangle). (B) Ducts were superfused with HEPES buffered solution for 10 minutes (data not shown) and then the perfusate was switched to $\mathrm{HCO}_{3}-\mathrm{CO}_{2}$ buffered solution. After 10 minutes of superfusion with $\mathrm{HCO}_{3}{ }^{-} / \mathrm{CO}_{2}$ buffered solution, ducts were exposed to $10 \mu \mathrm{M}$ forskolin. From 20 minutes, ducts were exposed either to no blocker (only forskolin stimulation, filled square) or to $100 \mu \mathrm{M}$ bumetanide (empty triangle). (C) Ducts were superfused with HEPES buffered solution for 10 minutes (data not shown) and then the perfusate was switched to $\mathrm{HCO}_{3}{ }^{-} / \mathrm{CO}_{2}$ buffered solution. From 10 minutes, ducts were exposed either to $100 \mu \mathrm{M}$ bumetanide (empty triangle), or no blocker (filled square). From 20 minutes, all ducts were exposed to $10 \mu \mathrm{M}$ forskolin. (D) Ducts were superfused with HEPES buffered solution for 10 minutes (data not shown) and then the perfusate was switched to $\mathrm{HCO}_{3}{ }^{-} / \mathrm{CO}_{2}$ buffered solution. After 10 minutes of superfusion with $\mathrm{HCO}_{3}{ }^{-} / \mathrm{CO}_{2}$ buffered solution, ducts were exposed to $10 \mu \mathrm{M}$ forskolin. From 20 minutes ducts were exposed to $3 \mu \mathrm{M}$ EIPA and $100 \mu \mathrm{M}$ DIDS (empty square). Administration of EIPA and DIDS without bumetanide did not cause statistically significant reduction in forskolin-evoked fluid secretion. Changes in relative luminal volume $\left(V_{\mathrm{r}}\right)$ are shown. Data was obtained from five ducts isolated from at least three different animals in each series and is presented as the mean \pm SEM.

\section{Carbachol-Stimulated Fluid Secretion of LG Interlobular Ducts}

The effect of carbachol treatment on fluid secretion of LG ducts was investigated both in HEPES buffered and in $\mathrm{HCO}_{3}{ }^{-}$/ $\mathrm{CO}_{2}$ buffered solutions. In the first series of experiments, ducts were perfused with HEPES buffered solutions for 10 minutes, followed by administration of $100 \mu \mathrm{M}$ carbachol to the bath solution. No secretion was observed in HEPES buffered solution, whereas carbachol initiated ductal swelling representing cholinergic-evoked ductal fluid secretion. Fluid secretion proved to be biphasic consisting of a continuous swelling in the first 5 minutes followed by a plateau phase (secretory rate in the first 5 minutes of stimulation: $122.3 \pm 29.6 \mathrm{pL} / \mathrm{min} /$ $\mathrm{mm}^{2}$, in the first 10 minutes of stimulation: $69.2 \pm 12.9 \mathrm{pL} /$ $\mathrm{min} / \mathrm{mm}^{2}$; Fig. $5 \mathrm{~A}$ ).

The role of $\mathrm{HCO}_{3}{ }^{-}$in carbachol-evoked fluid secretion was investigated in the second series of experiments. Ducts were perfused with $\mathrm{HCO}_{3}{ }^{-} / \mathrm{CO}_{2}$ buffered solution. Ducts did not show fluid secretion in $\mathrm{HCO}_{3}{ }^{-} / \mathrm{CO}_{2}$ buffered solution. One hundred micromols of carbachol was then administered to the bath and the swelling response was detected. Figure 4B shows mean data for the change in relative volume. The kinetics of carbachol-stimulated ductal fluid secretion was very similar to those that observed in HEPES buffered solution. The stimulatory effect of carbachol could be detected in the first 5 minutes, followed by a plateau phase (secretory rate in the first 5 minutes of stimulation: $106.3 \pm 26.7 \mathrm{pL} / \mathrm{min} / \mathrm{mm}^{2}$, in the first 10 minutes of stimulation: $66.3 \pm 15.6 \mathrm{pL} / \mathrm{min} / \mathrm{mm}^{2}$; Fig. $5 \mathrm{~B})$.

Administration of parasympatholytic atropine $(10 \mu \mathrm{M})$ resulted in a complete abolishment of carbachol-evoked fluid secretion both in HEPES buffered and in $\mathrm{HCO}_{3}{ }^{-} / \mathrm{CO}_{2}$ buffered solutions (Figs. 5A, 5B). Secretory rates did not show a significant difference between measurements in HEPES buffered and $\mathrm{HCO}_{3}{ }^{-} / \mathrm{CO}_{2}$ buffered solutions. Secretory rates evoked by forskolin and carbachol in the presence and in the absence of $\mathrm{HCO}_{3}{ }^{-}$are summarized in Figure 6 .

\section{Discussion}

In the present work, we provide the quantification of water permeability of lacrimal ducts, as well as the experimental evidence of lacrimal duct fluid secretion evoked by forskolin or carbachol.

Until recently, neither experimental methods, nor results deriving from functional experiments have been published concerning the fluid secreting capability of the LG duct epithelium. In contrast to many secretory epithelia, there is a lack of published calculation of the water permeability of the duct epithelium, even though this parameter is essential in determining the fluid transport. It has been estimated that duct cells may produce up to $30 \%$ of the total volume of the LG fluid, thus the relative contribution of duct epithelial cells to 

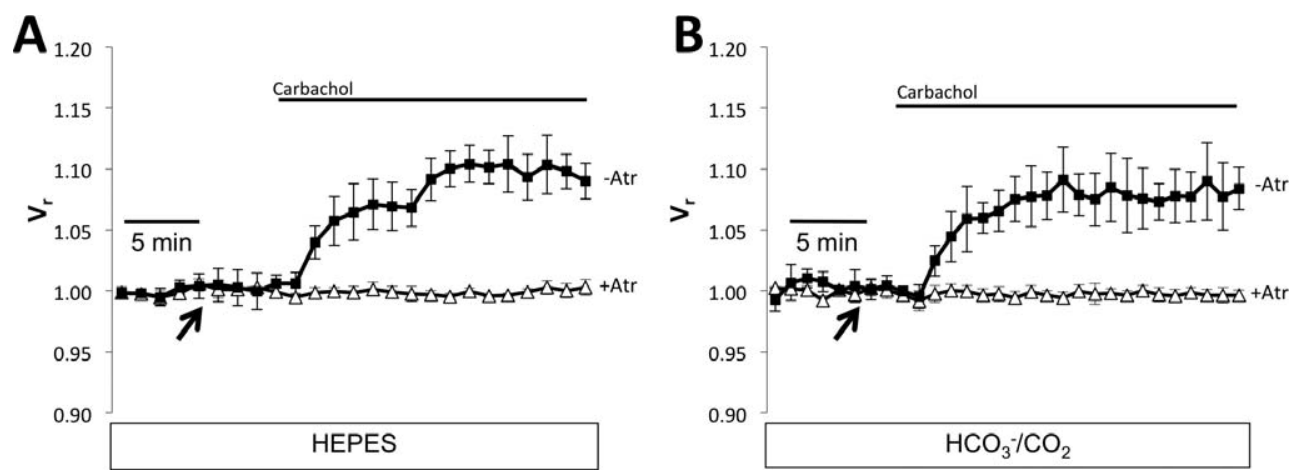

Figure 5. Effect of carbachol on ductal fluid secretion in LG gland interlobular ducts in the presence or in the absence of $\mathrm{HCO}_{3}{ }^{-}$. (A) Ducts were superfused with HEPES buffered solution throughout the experiments. From 5 minutes ducts were exposed either to $100 \mu \mathrm{M}$ atropine (empty triangle, arrow indicates the initiation of atropine treatment) or no blocker (filled square). From 10 minutes all ducts were exposed to $100 \mu \mathrm{M}$ carbachol. (B) Ducts were superfused with HEPES buffered solution for 10 minutes (data not shown) and then the perfusate was switched to $\mathrm{HCO}_{3}{ }^{-} / \mathrm{CO}_{2}$ buffered solution. From 5 minutes, ducts were exposed either to $100 \mu \mathrm{M}$ atropine (empty triangle, arrow indicates the initiation of atropine treatment) or no blocker (filled square). From 10 minutes, all ducts were exposed to $100 \mu \mathrm{M}$ carbachol. Changes in the relative luminal volume $\left(V_{\mathrm{r}}\right)$ are shown. Data was obtained from five ducts isolated from at least three different animals in each series and is presented as the mean \pm SEM.

water secretion cannot be neglected. ${ }^{6,7}$ However the relative inaccessibility of the LG duct structure makes it difficult to obtain information from viable duct segments.

The LG isolation technique described earlier by our laboratory results in viable duct segments maintained in short-term culture, which are suitable for functional studies. ${ }^{12}$ According to our observations, the sealing of the ends of the ducts results in complete restoration of epithelial integrity and swelling of the ducts happens without leakage in the vast majority of cases. For the first time, video microscopic method was applied to investigate the osmotic permeability and secretory properties of LG duct epithelium in the present work.

The value of $P_{\mathrm{f}}$ proved to be $60.53 \pm 19.76 \mu \mathrm{m} / \mathrm{s}$. This $P_{\mathrm{f}}$ value is lower than the highly water permeable pancreatic duct epithelium (160-170 $\mu \mathrm{m} / \mathrm{s}$, measured in rat pancreatic ducts) ${ }^{24,26}$ or the kidney proximal tubule $(100-500 \mu \mathrm{m} / \mathrm{s}$, different species $)^{27,28}$ and very similar to the distal airways of the guinea pig $(60 \mu \mathrm{m} / \mathrm{s}),{ }^{29}$ to the rat cholangiocytes $(50 \mu \mathrm{m} /$ s), ${ }^{30}$ and to the cultured corneal endothelium in mice $(74 \mu \mathrm{m} /$ secretion in the corresponding buffer solutions without stimulatory agent). ${ }^{*} P<0.001$. sufficient to support the process of fluid secretion, and proves that rabbit LG duct epithelium can be able to secrete fluid.

Until recently, limited number of studies has focused on LG duct epithelium. ${ }^{11,12,32-36}$ All of these studies investigated the ion secretory profile of duct cells, while fluid secretory properties of duct system remained speculative. Dartt et al. ${ }^{6}$ published a landmark study in 1981 proposing that the electrolyte and water component of LG fluid could be a mixture of plasma-like primary fluid secreted by the acinar cells and a potassium ion-rich fluid produced by the duct cells. They concluded that duct cells may secrete a significant portion of LG fluid. Ding et al. ${ }^{32}$ recently established a nomenclature for the lacrimal duct system in the rabbit. According to their description, lacrimal duct system can be divided into intralobular, interlobular, intralobar, and interlobar ducts. The gene expression profile of these various duct segments and the acinar cells were analyzed using laser capture microdissection and real-time RT-PCR. Marked difference could be measured among distinct duct segments suggesting their differing role in tear secretion. In general, predominant expression of cystic fibrosis transmembrane conductance

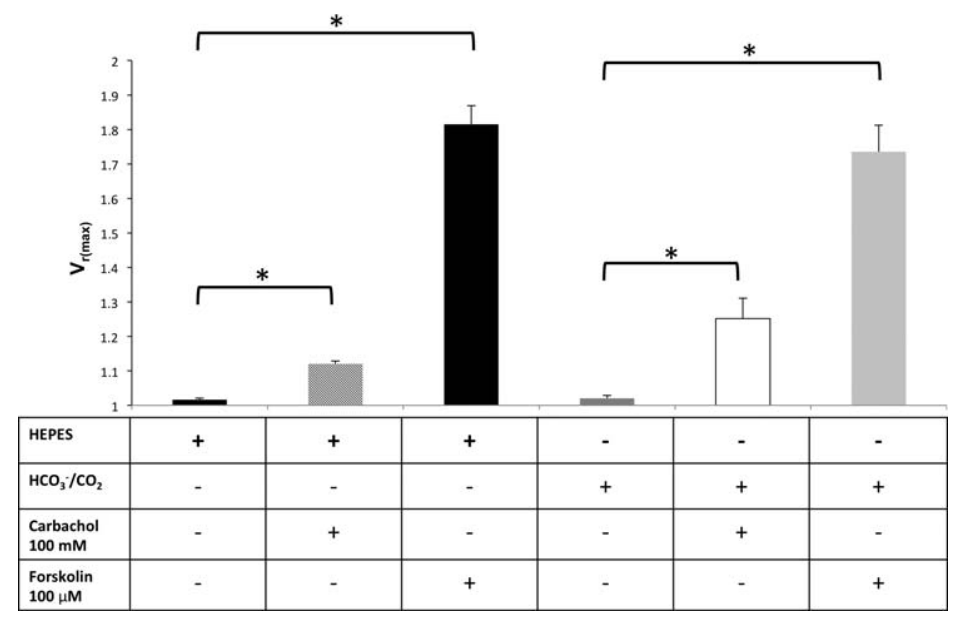

Figure 6. Calculated secretory rates of LG interlobular ducts evoked by forskolin and carbachol. Secretory rates $\left(J_{v}\right)$ were calculated from data shown in Figures 2 and 4 and are expressed in picoliter secreted fluid per minute per millimeter squared luminal epithelial surface. Secretory rates were calculated from the change in relative luminal volume in the first 10 minutes of carbachol or forskolin stimulation. Secretory rates evoked by carbachol or by forskolin both in HEPES buffered and $\mathrm{HCO}_{3}{ }^{-} / \mathrm{CO}_{2}$ buffered solutions were significantly higher, compared with controls (i.e., fluid 


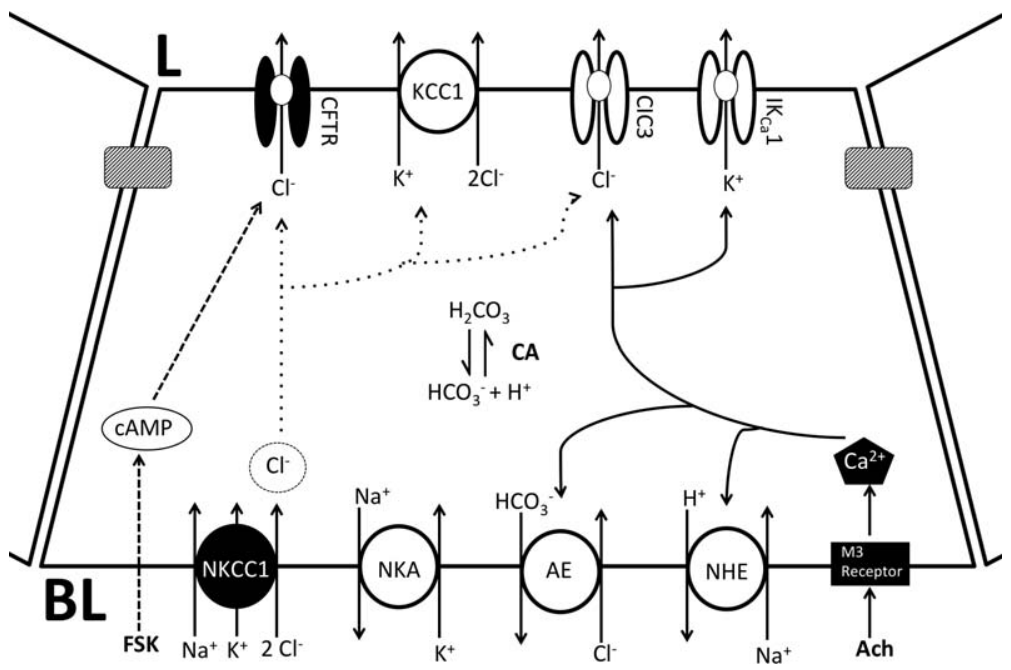

FigurE 7. Schematic model of electrolyte secretion underlying fluid secretion in LG interlobular duct epithelial cells. The model is based on the channels and transporters identified by Dartt et al., ${ }^{6}$ Ubels et al. ${ }^{11}$ Ding et al.,${ }^{32}$ our earlier investigations, ${ }^{12}$ and by the present study. Forskolinstimulation results in elevated cytosolic cAMP levels which activate $\mathrm{Cl}^{-}$secretion through CFTR. Summarized actions of $\mathrm{Cl}^{-}$selective channels located on the apical membrane of the duct cells result in intraluminal flux of chloride. Elevation of intraluminal $\mathrm{Cl}^{-}$concentration is the main determinant of lumen-negative transepithelial voltage difference, which is the driving force of ductal fluid secretion. Coupled influxes of $\mathrm{Na}^{+}$, $\mathrm{K}^{+}$, and $\mathrm{Cl}^{-}$are mediated by bumetanide-sensitive NKCC1 located on the basolateral membrane. Parasympathomimetic carbachol stimulates NHE activity, followed by the activation of $\mathrm{AE}$ on the basolateral membrane through $\mathrm{Ca}^{2+}$ signaling. The elevated intracellular $\mathrm{Ca}^{2+}$ concentration can also activate IKCa1, a Ca ${ }^{2+}$-activated potassium channel and $\mathrm{ClC} 3$, an apically located $\mathrm{Cl}^{-}$channel. L, luminal side; $\mathrm{Bl}$, basolateral side; $\mathrm{KCC}^{+}, \mathrm{K}^{+} / 2 \mathrm{Cl}^{-}$ cotransporter; $\mathrm{ClC}$, Chloride channel; IKCa1, intermediate conductance calcium-activated $\mathrm{K}^{+}$channel; NKA, $\mathrm{Na}^{+} / \mathrm{K}^{+}$-ATPase.

regulator (CFTR) was found in the duct cells. ${ }^{32}$ Another recent study $^{33}$ found significant variations in the expression of different $\mathrm{Cl}^{-}$channels in a rabbit model of Sjögren syndrome and in healthy animals. The reduced levels of NKCC1 and CFTR mRNA in duct cells derived from diseased animals suggest the active contribution of these structures in altered lacrimal fluid secretion. In a recent paper, Lu and Ding ${ }^{36}$ elegantly demonstrated that CFTR is functionally involved in $\mathrm{Cl}^{-}$transport in both acinar and duct cells in the rabbit LG and suggests that CFTR plays a significant role in LG function. The presence of significant amounts of CFTR and other channels and transporters in the LG duct cells strongly suggests that LG ducts play a critical role in the maintenance of homeostasis of lacrimal fluid secretion.

In the present work, we found that forskolin initiated a brisk and continuous swelling response in rabbit LG interlobular ducts. Fluid secretion was almost unaffected by inhibition of $\mathrm{HCO}_{3}{ }^{-}$transport mechanisms, but was completely abolished when basolateral $\mathrm{Cl}^{-}$uptake was blocked by bumetanide. Inhibitory effect of bumetanide proved to be very similar in the case of acute and chronic administration demonstrating the inability of one basolateral transport pathway (EIPA and DIDS sensitive) to increase its activity when another (bumetanidesensitive) is chronically inhibited. A model summarizing the channels, transporters, and intracellular messengers is shown in Figure 7. Both elevated cytosolic cAMP levels and intracellular $\mathrm{Ca}^{2+}$ signaling can activate $\mathrm{Cl}^{-}$secretion through different $\mathrm{Cl}^{-}$selective channels located on the apical membrane. Summarized actions of these $\mathrm{Cl}^{-}$channels result in intraluminal flux of chloride. Elevation of intraluminal $\mathrm{Cl}^{-}$ concentration can be the main determinant of lumen-negative transepithelial voltage difference, which is the driving force of ductal fluid secretion.

The complete inhibition of fluid secretion by bumetanide in $\mathrm{HCO}_{3}{ }^{-} / \mathrm{CO}_{2}$ buffered solution suggests the predominant role of $\mathrm{Cl}^{-}$transport mechanisms over $\mathrm{HCO}_{3}{ }^{-}$secreting processes in lacrimal duct fluid secretion in rabbit. As bumetanide is a wellknown inhibitor of the NKCC1 located on the basolateral membrane of the duct cells, this transport process can be the main route of cellular chloride uptake. Further studies are needed to determine the functional activity of this transporter. Our findings strongly suggest the importance of CFTR in ductal fluid secretion as forskolin, a well-known activator of CFTR via the elevation of cytosolic cAMP levels, resulted in a significant swelling response in our experiments. We were unable to carry out direct investigation of the apically located CFTR since the luminal space cannot be reached in sealed ducts. Cannulation of these narrow and fragile structures needs further development of our experimental technique.

Cholinergic control of LG secretion through M3 muscarinic receptors is well known. ${ }^{6,10,11,37-43}$ Cholinergic stimulation with carbachol resulted in a biphasic secretory response with a faster initial and a plateau second phase in our experiments. The carbachol-evoked secretory pattern of lacrimal ducts was similar to those found in pancreatic ducts. ${ }^{22}$ Parasympatholytic atropine abolished the stimulatory effect of carbachol, suggesting the involvement of muscarinic cholinoceptors. The secretory effects of forskolin were remarkably higher compared with the response to carbachol stimulation.

Interlobular ducts are the smallest segments, which can be isolated with our technique. Considering the presumably different function of various duct segments suggested by earlier investigations it must be emphasized that data obtained from one specified section of the duct system can only be translated to other parts of the ductal tree with great precaution.

In conclusion, calculated values of filtration permeability and forskolin- and carbachol-induced fluid secretory capabilities of LG duct cells were demonstrated in the present work. These results were achieved by an experimental technique used by the first time in lacrimal duct research. Our results strongly support the hypothesis that the LG duct system is actively involved in lacrimal fluid secretion. Our novel experimental technique opens a new horizon in the investigation of lacrimal duct function and can help to clarify the effects of various stimulatory agents and the role of ion transport 
mechanisms in tear secretion. Effects of potential secretagouge compounds can also be tested with this method. These future results may contribute to the development of targeted pharmacological interventions in order to improve deteriorated LG functions in dry eye disease.

\section{Acknowledgments}

This work was supported by Grants TÁMOP-4.2.2./B-10/1-20100012, TÁMOP-4.2.2.A-11/1/KONV-2012-0035, and TÁMOP 4.2.4.A A2-SZJÖ-TOK-13-0017 (TÁMOP, Hungary).

Disclosure: M. Katona, None; E. Vizvári, None; L. Németh, None; A. Facskó, None; V. Venglovecz, None; Z. Rakonczay Jr, None; P. Hegyi, None; E. Tóth-Molnár, None

\section{References}

1. Hemady R, Chu W, Foster CS. Keratoconjunctivitis sicca and corneal ulcers. Cornea. 1990;9:170-173.

2. The definition and classification of dry eye disease: report of the Definition and Classification Subcommittee of the International Dry Eye WorkShop. Ocul Surf. 2007;5:75-92.

3. Paulsen F, Langer G, Hoffmann W, Berry M. Human lacrimal gland mucins. Cell Tissue Res. 2004;316:167-177.

4. Millar TJ, Herok G, Koutavas H, Martin DK, Anderton PJ. Immunohistochemical and histochemical characterisation of epithelial cells of rabbit lacrimal glands in tissue sections and cell cultures. Tissue Cell. 1996;28:301-312.

5. Martin CL, Munnell J, Kaswan R. Normal ultrastructure and histochemical characteristics of canine lacrimal glands. $\mathrm{Am} \mathrm{J}$ Vet Res. 1988;49:1566-1572.

6. Dartt DA Moller M, Poulsen JH. Lacrimal gland electrolyte and water secretion in the rabbit: localization and role of $\left(\mathrm{Na}^{+}+\right.$ $\mathrm{K}^{+}$)-activated ATP-ase. J Physiol. 1981;321:557-569.

7. Mircheff AK. Control of lacrimal gland function: water and electrolyte secretion and fluid modification. In: DM, Albert, Jakobiec FA, eds. Principles and Practice in Ophthalmology. Philadelphia, PA: WB Saunders; 1994:466-472.

8. Walcott B, Birzgalis A, Moore LC, Brink PR. Fluid secretion and the $\mathrm{Na}^{+}-\mathrm{K}^{+}-2 \mathrm{Cl}^{-}$cotransporter in mouse exorbital lacrimal gland. Am J Physiol Cell Physiol. 2005;289:C860-C867.

9. Dartt DA. Regulation of lacrimal gland secretion by neurotransmitters and the EGF family of growth factors. Exp Eye Res. 2001;73:741-752.

10. Dartt DA. Neural regulation of lacrimal gland secretory processes: relevance in dry eye diseases. Prog Retin Eye Res. 2009;28:155-177.

11. Ubels JL, Hoffman HM, Srikanth S, Resau JH, Webb CP. Gene expression in rat lacrimal gland duct cells collected using laser capture microdissection: evidence for $\mathrm{K}+$ secretion by the duct cells. Invest Ophthalmol Vis Sci. 2006;47:1876-1885.

12. Toth-Molnar E, Venglovecz V, Ozsvari B, et al. New experimental method to study acid/base transporters and their regulation in lacrimal gland ductal epithelia. Invest Ophthalmol Vis Sci. 2007;48:3746-3755.

13. Argent BE, Arkle S, Cullen MJ, Green R. Morphological, biochemical and secretory studies on rat pancreatic ducts maintained in tissue culture. Q J Exp Physiol. 1986;71:633648.

14. Ishiguro H, Steward MC, Wilson RW, Case RM. Bicarbonate secretion in interlobular ducts from quinea-pig pancreas. $J$ Physiol. 1996;495.1:179-191.

15. Ishiguro H, Naruse $S$, Steward MC, et al. Fluid secretion in interlobular ducts isolated from guinea-pig pancreas. J Physiol. 1998;511:407-422.

16. Hegyi P, Rakonczay $Z \mathrm{~J}$ r. The inhibitory pathways of pancreatic ductal bicarbonate secretion. Int J Biochem Cell Biol. 2007; 39:25-30.
17. Szalmay G, Varga G, Kajiyama F, et al. Bicarbonate and fluid secretion evoked by cholecystokinin, bombesin and acetylcholine in isolated guinea-pig pancreatic ducts. $J$ Physiol. 2001;535.3:795-807.

18. Martinez JR. Cellular mechanisms underlying the production of primary secretory fluid in salivary glands. Critic Rev Oral Biol Med. 1990;1:67-78.

19. Tandler B, Pinkstaff CA, Phillips CJ. Interlobular excretory ducts of mammalian salivary glands: structural and histochemical review. Anat Rec A Discov Mol Cell Evol Biol. 2006;288: 498-526.

20. Roussa E. Channels and transporters in salivary glands. Cell Tissue Res. 2011;343:263-287.

21. Bandyopadhyay BC, Swaim WD, Sarkar A, Liu X, Ambudkar IS. Extracellular $\mathrm{Ca}^{2+}$ sensing in salivary ductal cells. J Biol Chem. 2012;287:30305-30316.

22. Fernández-Salazar MP, Pascua P, Calvo JJ, et al. Basolateral anion transport mechanisms underlying fluid secretion by mouse, rat and guinea-pig pancreatic ducts. J Physiol. 2004;556.2:415428.

23. Pascua P, Garcia M, Fernández-Salazar MP, et al. Ducts isolated from the pancreas of CFTR-null mice secrete fluid. Pflugers Arch. 2009; 459:203-214.

24. Ko SBH, Naruse S, Kitagawa M, et al. Aquaporins in rat pancreatic interlobular ducts. Am J Physiol Gastrointest Liver Physiol. 2002;282:G324-G331.

25. Mlekoday HJ, Moore R, Levitt DG. Osmotic water permeability of the human red cell. Dependence on direction of water flow and cell volume. J Gen Physiol. 1983;81:213-220.

26. Burghardt B, Nielsen S, Steward MC. The role of aquaporin water channels in fluid secretion by the exocrine pancreas. $J$ Membr Biol. 2006;210:143-153.

27. Berry CA. Water permeability and pathways in the proximal tubule. Am J Physiol Renal Physiol. 1983;245:F279-F294.

28. Berry CA, Verkman AS. Osmotic gradient dependence of osmotic permeability in rabbit proximal convoluted tubule. $J$ Membr Biol. 1988;105:33-43.

29. Folkesson HG, Matthay MA, Frigeri A, Verkman AS. Transepithelial water permeability in microperfused distal airways. Evidence for channel-mediated water transport. J Clin Invest. 1996;97:664-671.

30. Roberts SK, Yano M, Ueno Y, et al. Cholangiocytes express the aquaporin CHIP and transport water via a channel-mediated mechanism. Proc Natl Acad Sci U S A. 1994;91:13009-13013.

31. Kuang K, Yiming M, Wen Q, et al. Fluid transport across cultured layers of corneal endothelium from aquaporin-1 null mice. Exp Eye Res. 2004;78:791-798.

32. Ding C, Parsa L, Nandoskar P, Zhao P, Wu K, Wang Y. Duct system of the rabbit lacrimal gland: structural characteristics and role in lacrimal secretion. Invest Ophthalmol Vis Sci. 2010;51:2960-2967.

33. Nandoskar P, Wang Y, Wei R, et al. Changes of chloride channels in the lacrimal glands of a rabbit model of Sjögren syndrome. Cornea. 2012;31:273-279.

34. Ding C, Nandoskar P, Lu M, Thomas P, Trousdale MD, Wang Y. Changes of aquaporins in the lacrimal glands of a rabbit model of Sjögren's syndrome. Curr Eye Res. 2011;36:571-578.

35. Ding C, Lu M, Huang J. Changes of the ocular surface and aquaporins in the lacrimal glands of rabbits during pregnancy. Mol Vis. 2011;17:2847-2855.

36. Lu M, Ding C. CFTR-mediated $\mathrm{Cl}^{-}$transport in the acinar and duct cells of rabbit lacrimal gland. Curr Eye Res. 2012;37:671677.

37. Herzog V, Sies H, Miller F. Exocytosis in secretory cells of rat lacrimal gland. Peroxidase release from lobules and isolated cells upon cholinergic stimulation. J Cell Biol. 1976;70:692706. 
38. Dartt DA, Botelho SY. Protein in rabbit lacrimal gland secretion. Invest Ophthalmol Vis Sci. 1979;18:1207-1209.

39. Ubels JL, Foley KM, Rismondo V. Retinol secretion by the lacrimal gland. Invest Ophthalmol Vis Sci. 1986;27:12611268.

40. Dartt DA, Hodges RR. Cholinergic agonists activate P2X receptors to stimulate protein secretion by the rat lacrimal gland. Invest Ophthalmol Vis Sci. 2011;52:3381-3390.
41. Hootmann SR, Picardo-Leonard TM, Burnham DB. Muscarinic acetylcholine receptor structure in acinar cells of mammalian exocrine glands. J Biol Chem. 1985;260:4186-4194.

42. Mauduit P, Jammes H, Rossignol B. M3 muscarinic acetylcholine receptor coupling to PLC in rat exorbital lacrimal acinar cells. Am J Physiol. 1993;264(6 Pt 1);1550-1560.

43. Ding C, Walcott B, Keyser KT. Neuronal nitric oxide synthase and the autonomic innervations of the mouse lacrimal gland. Invest Ophthalmol Vis Sci. 2001;42:2789-2794. 